\title{
A PRÁTICA PEDAGÓGICA DO ENSINO DE EDUCAÇÃO AMBIENTAL NAS ESCOLAS PÚBLICAS DE JOÃO CÂMARA - RN
}

\author{
Vanda Maria Saraiva \\ Professora do Departamento Acadêmico de Recursos Naturais do Centro Federal de \\ Educação Tecnológica do Rio Grande do Norte; Graduada em Biologia e Mestre em \\ Genética pela Universidade Federal da Paraíba. \\ adnav@cefetrn.br
}

Kelly Regina Pereira do Nascimento

Técnica em Controle Ambiental pelo CEFET-RN. krnascimento8@gmail.com

Renata Kelly Matos da Costa

Técnica em Controle Ambiental pelo CEFET-RN.

\section{RESUMO}

O presente projeto de pesquisa foi desenvolvido em três escolas públicas (Cenecista João XXIII, Francisco de Assis Bittencourt e Antônio Gomes) da cidade de João Câmara-RN, com o objetivo geral de conhecer a realidade dessas escolas, no sentido de saber se existe uma prática permanente das questões ambientais nos currículos escolares e se estes são passados aos alunos de forma multidisciplinar, como determina os Parâmetros Curriculares Nacionais - PCNs, que dá evidência necessária a preservação do meio ambiente, contemplando as realidades locais e sugere formas de introdução de Educação Ambiental (EA) nos currículos. A Constituição Federal também estabelece como competência do poder público, promover a EA em todos os níveis de ensino. Considerando que a degradação ambiental é hoje uma das maiores preocupações dos governos e da sociedade, faz-se necessário desenvolver ações de caráter educativo, para o desenvolvimento sustentável garantindo assim, a permanência dos recursos naturais em condições que assegure às gerações futuras sobrevivência na Terra. A metodologia utilizada foi a pesquisa exploratória, pois levantamos informações sobre o nosso objeto de estudo, e do tipo explicativa uma vez que analisamos o fenômeno estudado, os seus "porquês" e seus determinantes. Visitamos as escolas para buscarmos os dados "in loco", onde foram feitos levantamentos através de perguntas a respeito do assunto abordado. Aplicamos um questionário com os docentes, com perguntas objetivas e subjetivas, respondidos por 35 professores de um total de 55, representando assim 64\% da amostra. Os resultados obtidos nas três escolas foram analisados conjuntamente. Após a aplicação do questionário, seguiuse a fase da análise de todos os dados obtidos durante a pesquisa. Buscou-se dessa forma, distribuir graficamente em termos quantitativos os resultados das respostas do questionário, as quais foram interpretadas quantitativamente e verificamos que a temática é pouco trabalhada pelos professores dessas escolas, e que os mesmos precisam de apoio dos governos para que seja efetiva a participação da comunidade escolar.

PALAVRAS-CHAVE: Educação Ambiental, PCNs, Escolas. 


\title{
THE TEACHING'S PEDAGOGICAL PRATICE OF ENVIRONMENTAL EDUCATION ON THE SCHOOLS OF JOÃO CÂMARA - RN
}

\begin{abstract}
The present project of research was developed in three public schools (Cenecista João XXIII, Francisco de Assis Bittencourt and Antonio Gomes) of the city of Chamber João, with the general objective to know the reality of these schools, in the direction to know if permanent one of the ambient questions in the pertaining to school resumes exists one practical and if these are passed to the pupils of transversal form, as it determines the Nationals Curricular Parameters - PCNs, that of the evidence the preservation of the environment, having contemplated the local realities and suggest forms of introduction of Environmental Education (EA) in the resumes. The Federal Constitution also establishes as ability of the public power, to promote the EA in all the education levels. Considering that the environmental degradation is today one of the biggest concerns of the governments and the society, one becomes necessary to develop action of educative character, for the sustainable development thus guaranteeing, the permanence of the natural resources in conditions that survival in the Land assures to the future generations. The used methodology was the exploratory research, therefore we raise information on our object of study, and the clarifying type a time that we analyze the studied phenomenon, its "reasons" and its determinative ones. We visit the schools to search the data "in loco", where surveys through questions regarding the boarded subject had been made. We apply a questionnaire with the professors, objective and subjective questions, answered for 35 professors of a total of 55, thus representing $64 \%$ of the sample. The results gotten in the three schools had been analyzed jointly. After the application of the questionnaire, followed it phase of the analysis of all the data gotten during the research, searching of this form, to graphically distribute in quantitative terms the results of the answers of the questionnaire, which had been interpreted and verify that the thematic one little is worked by the professors of these schools, and that the same ones need support of the governments, of the direction of the school and the city department of education in partnership with of environment and urbanism, so that either effective the participation of the pertaining to school community.
\end{abstract}

KEY-WORDS: Environmental Education, PCNs, Schools. 


\section{A PRÁTICA PEDAGÓGICA DO ENSINO DE EDUCAÇÃO AMBIENTAL NAS ESCOLAS PÚBLICAS DE JOÃO CÂMARA - RN}

\section{INTRODUÇÃO}

Desde os primórdios muitas sociedades humanas, que se tornaram hegemônicas em diferentes épocas históricas, buscaram acumular riquezas, utilizaram todos os recursos à sua volta. Os recursos ambientais são finitos, limitados e estão dinamicamente interrelacionados, a diminuição drástica de um pode causar o mesmo em outro, aparentemente não relacionado a ele. Para a reversão desta situação, o homem percebeu a necessidade de repensar seu modelo de crescimento econômico e desenvolvimento social, criou leis que prevêem multas e privação da liberdade, mas estas medidas não foram suficientes e decidiu associar o processo educativo para conceber pessoas conscientes de seus deveres e direitos coletivos. Por isso é indispensável que a Educação Ambiental faça parte dos projetos políticos pedagógicos das escolas e que seja abordada como um tema transversal.

A temática (Educação Ambiental) foi escolhida com o intuito de verificar se está sendo passado para os alunos, na prática, ou se continua só na teoria dos Parâmetros Curriculares Nacionais-PCNs.

Esta pesquisa tornou-se pertinente pelo fato de poder viabilizar novas formas de avaliar as ações de Educação Ambiental, que já são ou podem vir a ser desenvolvidas nas escolas públicas de João Câmara - RN, podendo servir como instrumento para subsidiar melhorias no ensino de educação ambiental nas escolas objeto de estudo.

Na área da cidade de João Câmara onde se localizam essas escolas estão situadas, pode ser observado lixo jogado na rua; alimentos armazenados indevidamente; a coleta de lixo promovida pela prefeitura é destinada ao lixão; por falta de saneamento básico na cidade, os moradores colocam água servida na rua, e sem esclarecimento, todas essas ações são praticadas por boa parte da população. Mas essa situação pode ser mudada, com escolas preparadas para tornar os alunos conscientes e multiplicadores em defesa do meio ambiente.

A Educação Ambiental, teoricamente, é tema transversal nos programas pedagógicos, porém, na prática isso não acontece. Falta incentivo e muitas vezes conhecimento do próprio professor nessa área. A sociedade não pode deixar que isso permaneça para benefício dessa e das futuras gerações.

O presente trabalho tem como objetivo geral fazer um diagnóstico da prática pedagógica do ensino de educação ambiental em três escolas do centro de João Câmara - RN.

\subsection{JUSTIFICATIVA}

A Constituição Federal estabelece como competência do poder público, promover a educação ambiental em todos os níveis de ensino. A nova proposta pedagógica, Parâmetros Curriculares Nacionais (PCNs), deu evidencia necessária às questões ambientais, contemplando as realidades locais e sugere formas de introdução de Educação Ambiental nos currículos. Considerando que a degradação ambiental é hoje uma das maiores preocupações dos governos e da sociedade, faz-se necessário desenvolver ações de caráter 
educativo, para o desenvolvimento sustentável garantindo assim, a permanência dos recursos naturais em condições que assegure às gerações futuras sobrevivência na Terra.

A educação ambiental visa contribuir para formação de cidadãos conscientes de suas responsabilidades com o meio ambiente, aptos a decidir e atuar em seu meio sócioambiental, comprometendo-se com o bem-estar de cada um e da sociedade como um todo. Mas para que isso aconteça, é preciso que a escola não trabalhe somente com informações e conceitos, ou seja, só na teoria, é importante que o tema transversal seja uma ferramenta utilizada para que o aluno possa aprender de forma dinâmica, maneiras para transformar a realidade em que vive.

Abordamos em nossa pesquisa três escolas públicas, sendo uma municipal (Colégio Cenecista João XXIII) e duas estaduais (Escola Estadual Antônio Gomes e Escola Estadual Francisco de Assis Bittencourt), na cidade de João Câmara-RN.

Essas escolas deveriam estar formando agentes multiplicadores em defesa do meio ambiente, mas na prática não é o que se observa, pois nesse bairro (Centro) são encontrados vários aspectos negativos, no que diz respeito à ação dos cidadãos em relação à Educação Ambiental.

\title{
2 REFERENCIAL TEÓRICO
}

A Educação Ambiental é um tema que deve ser obrigatoriamente abordado nas escolas, é multidimensional, ou seja, pode ser inserido em todas as disciplinas, pois o aprendizado está fundamentado na interdisciplidariedade, todas as matérias podem ser desenvolvidas na Educação Ambiental, ou vice-versa. Segundo Morin (2006, p. 39):

\begin{abstract}
A educação deve favorecer a aptidão natural da mente em formular e resolver problemas essenciais e, de forma correlata, estimular o uso total da inteligência geral. Este uso total pede o livre exercício da curiosidade, a faculdade mais expandida e a mais viva durante a infância e adolescência, que com freqüência a instrução extingue e que, ao contrário se trata de estimular ou, caso esteja adormecida de despertar.
\end{abstract}

Sem dúvida, a Educação Ambiental é indispensável na evolução educacional da sociedade que esta se adaptando a nova realidade mundial, que pede um comprometimento com o crescimento sustentável, sempre preservando os recursos naturais. Segundo Vilmar Berna (2004, p.18):

\footnotetext{
O ensino sobre o meio ambiente deve contribuir principalmente para o exercício da cidadania, estimulando a ação transformadora além de buscar aprofundar os conhecimentos sobre as questões ambientais de melhores tecnologias, estimular a mudança de comportamento e a construção de novos valores éticos menos antropocêntricos.
}

Os brasileiros possuem direitos e deveres assegurados pela constituição e a educação é um direito garantido. Segundo a Constituição da República Federativa do Brasil de 1988 no artigo 225, inciso primeiro do VI parágrafo, a Educação Ambiental deve ser abordada em todos os níveis de escolaridade: 
Promover a Educação Ambiental em todos os níveis de ensino e conscientização publica para a preservação do meio ambiente.

Todos têm direito ao meio ambiente ecologicamente correto, bem de uso comum do povo e essencial a sadia qualidade de vida, impondo-se ao poder público e a coletividade o dever de defender e preservá-lo para as presentes e futuras gerações.

Existe uma tendência em querer separar o conhecimento e/ou fragmentá-lo, como se não existisse uma ligação das partes, como se o conhecimento individual fosse por se só suficiente. Os problemas ambientais ocorrem em nível global, no entanto, também ocorre na escala local, quer dizer, está interligado, por isso é preciso é preciso aborda o global nas partes, assim como inserir as partes no global. Segundo Morin (2006, p.37):

O global é mais que o contexto, é o conjunto das diversas partes ligadas a ele de modo interrretroativo ou organizacional. Dessa maneira uma sociedade é mais que um contexto é o todo organizador de que fazemos parte. O todo tem qualidades ou propriedades que não são encontradas nas partes, se estas estiverem isoladas umas das outras, e certas qualidades ou propriedades das partes podem ser inibidas pelas restrições provenientes do todo.

Para abordar a Educação Ambiental em sala-de-aula é preciso mostrar aos alunos sua importância no contexto ambiental, é preciso que eles tenham consciência de que podem ser agentes transformadores, que podem mudar a realidade ao seu redor, e que essa realidade transformadora, transbordará em várias outras realidades, haverá a união das partes com o todo. Conforme Vilmar Berna (2004, p.30):

\footnotetext{
O educador ambiental deve procurar colocar os alunos em situações que sejam formadoras, como por exemplo, diante de uma agressão ambiental ou conservação ambiental, apresentando os meios de compreensão do meio ambiente. Em termos ambientais isso não constitui dificuldade, uma vez que o meio ambiente está em toda a nossa volta. Dissociada dessa realidade, a educação ambiental não teria razão de ser. Entretanto, mais importante que dominar informações sobre um rio ou ecossistema da região é usar o meio ambiente local como motivador.
}

De acordo com os Parâmetros Curriculares Nacionais (PCNs), a Educação Ambiental é um tema transversal e deve ser estudado em todas as séries e em todas as disciplinas, ou seja, independente da ciência que o professor lecionar ele deverá inserir temas ambientais.

\section{CARACTERIZAÇÃO DAS ESCOLAS}

O Colégio Municipal Cenecista João XXIII está localizado na Praça Monsenhor Freitas, $\mathrm{n}^{\circ}$ 188 no centro de João Câmara e dispõe de uma infra-estrutura capaz de atender a educação infantil e aos ensinos fundamental e médio, nos turnos: matutino, vespertino e noturno. $\mathrm{O}$ colégio possui em seu quadro de funcionários: 1 diretor, 1 supervisora, 1 orientador pedagógico, 1 secretário, 3 professores da educação infantil, 15 professores do ensino fundamental, 11 professores do ensino médio, 1 auxiliar administrativo, 2 auxiliares, 3 ASGs e 2 porteiros, para atender a 324 alunos. Mas em nossa pesquisa foram abordados apenas os professores do ensino médio. 


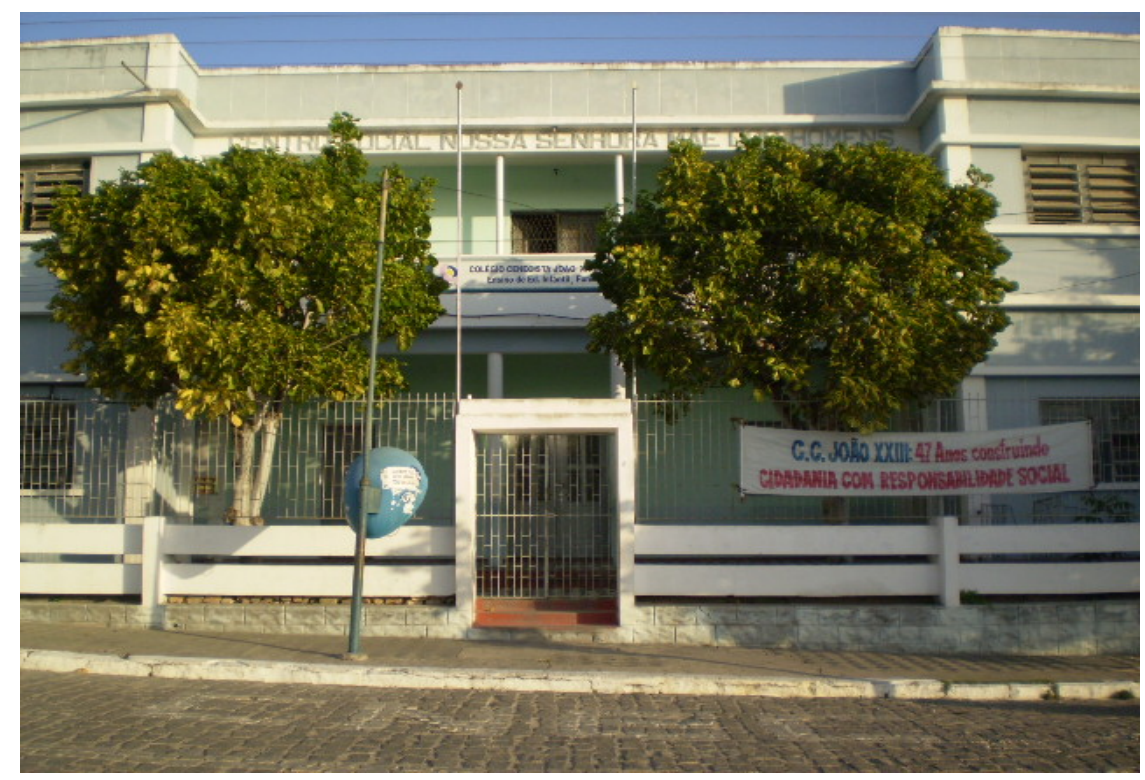

Figura 1 - Colégio Municipal Cenecista João XXIII.

A Escola Estadual Antônio Gomes está localizada na Rua Antônio Proença, nº 708 no centro de João Câmara. Oferece os ensinos fundamental e médio, nos turnos matutino, vespertino e noturno. Possui 1 diretor, 1 vice-diretor, 1 coordenador, 6 supervisores, 1 secretário, 21 professores do ensino fundamental, 13 professores do ensino médio, 4 auxiliares de secretaria, 2 porteiros e 1 merendeira. Para atender a 890 alunos.

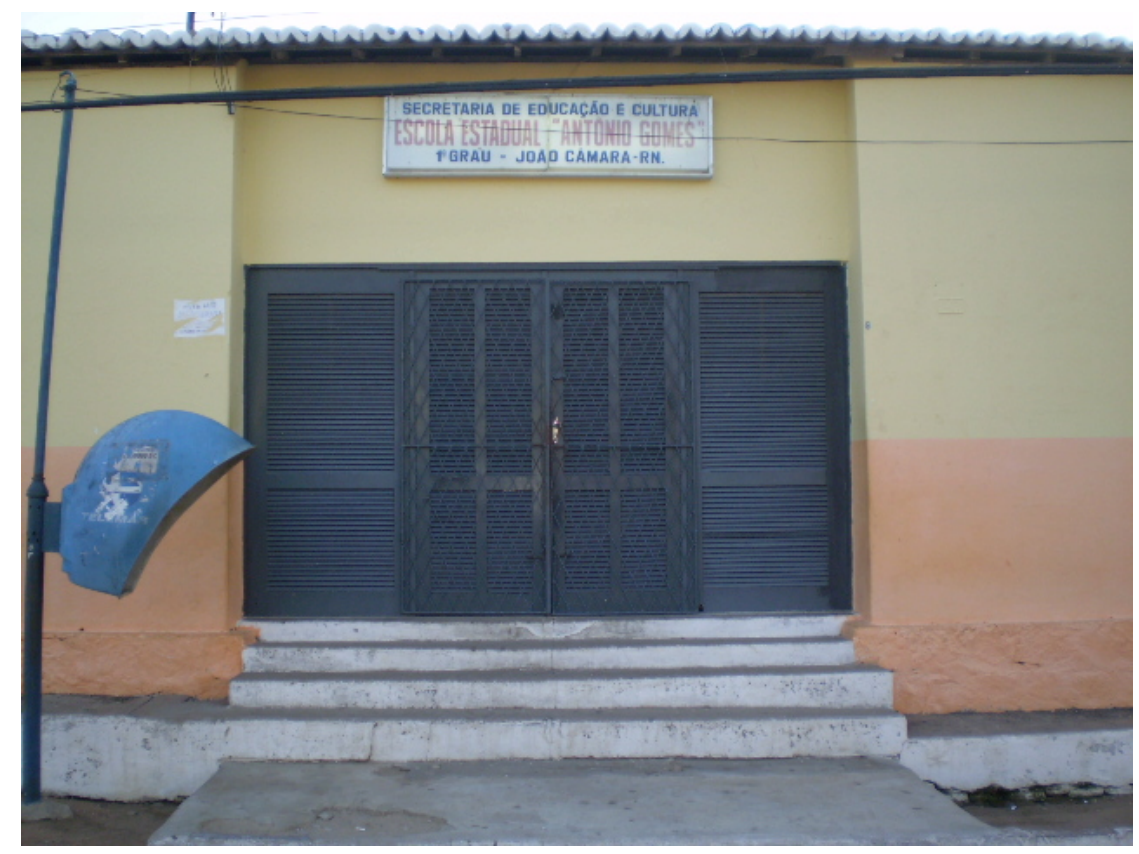

Figura 2 - Escola Estadual Antônio Gomes.

A Escola Estadual Francisco de Assis Bittencourt está localizada na Rua João Teixeira, $\mathrm{n}^{\circ}$ 56 no centro de João Câmara. Dispõe apenas do ensino médio, nos turnos: matutino, vespertino e noturno. Possui 1 diretor, 1 vice-diretor, 2 coordenadores, 3 supervisores, 1 secretário, 29 professores do ensino médio e 3 ASGs. Para atender a 1.271 alunos. 


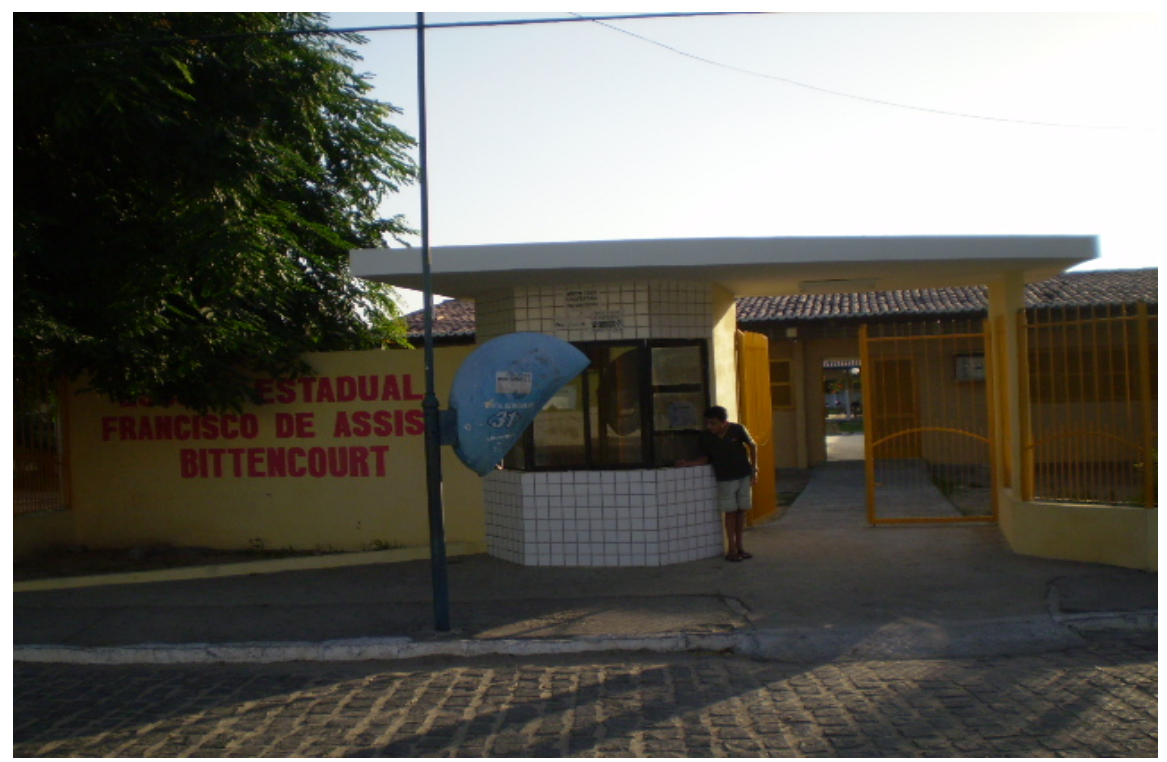

Figura 3 - Escola Estadual Francisco de Assis Bittencourt.

\section{METODOLOGIA}

Usamos no nosso trabalho a pesquisa exploratória, pois levantamos informações sobre o nosso objeto de estudo (Educação Ambiental nas escolas públicas do centro de João Câmara). Também utilizamos a pesquisa do tipo explicativa uma vez que analisamos o fenômeno estudado, os seus "porquês” e seus determinantes. Fomos a campo (Escolas) para buscarmos os dados diretamente no local, onde observamos e fizemos levantamentos, através de perguntas a respeito do assunto abordado. Aplicamos questionário com os docentes, onde constava 15 perguntas: sendo 12 objetivas e 3 subjetivas.

A escolha do questionário se deu pela objetividade das perguntas, o que nos ajudou a obter os dados estatísticos com maior precisão. Além disso, vale ressaltar que o anonimato dos informantes, no caso os professores, foi preservado. Antes de iniciarmos a aplicação do questionário, salientamos o quanto era importante a colaboração deles, e que era primordial a sinceridade no preenchimento do mesmo.

Do total de 11 professores do ensino médio do Colégio Cenecista João XXIII a pesquisa foi aplicada a todos. Na Escola Estadual Francisco de Assis Bittencourt do total de 29 professores do ensino médio a pesquisa foi aplicada a 17 professores. Na Escola Estadual Antônio Gomes do total 13 professores do ensino médio a pesquisa foi aplicada a 7 professores.

\section{ANÁLISE E DISCUSSÃO DOS RESULTADOS}

Após a aplicação do questionário, seguiu-se a fase da análise de todos os dados obtidos durante a pesquisa. Buscou-se dessa forma, distribuir graficamente em termos quantitativos os resultados das respostas do questionário, as quais foram interpretadas quantitativa.

Para tanto, foram analisados os seguintes indicadores de desempenho: as escolas analisadas não abordam a Educação Ambiental de forma significativa; também não desenvolvem uma programação real sobre o meio ambiente; os conteúdos ensinados nas escolas se detêm aos 
livros didáticos; em apenas umas das escolas (Colégio Cenecista João XXIII) constatamos a presença de um programa de educação ambiental que se denomina Grupo Ecológico.

Analisamos as três escolas conjuntamente para termos uma visão mais clara da temática em questão e para obter uma melhor comparação dos dados:

\section{COMO VOCÊ DESENVOLVE NA PRÁTICA, O ENSINO DA EDUCAÇÃO AMBIENTAL?}

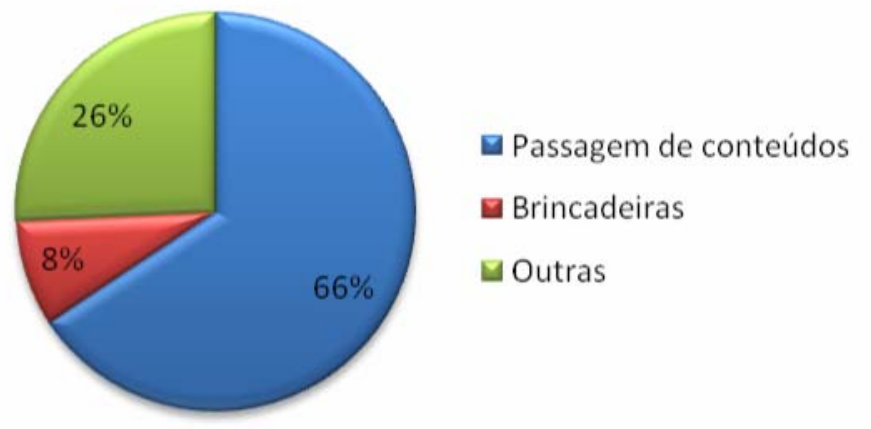

Figura 4 - Como você desenvolve na prática, o ensino da Educação Ambiental?

A figura 4 mostra que dos resultados obtidos nas três escolas, foi típica a opção de passagem dos conteúdos da educação formal (66\%), mostrando que essas instituições não seguem as orientações dos PCNs, de passarem em sua metodologia o tema Educação Ambiental, transversalmente, por todos as disciplinas e áreas. Apenas $8 \%$ fazem isso em forma de brincadeiras, com o objetivo de tornar o tema mais atrativo para os alunos; $26 \%$ abordam o assunto de outras formas; nas aulas de artes o tema não é contemplado em nenhum momento.

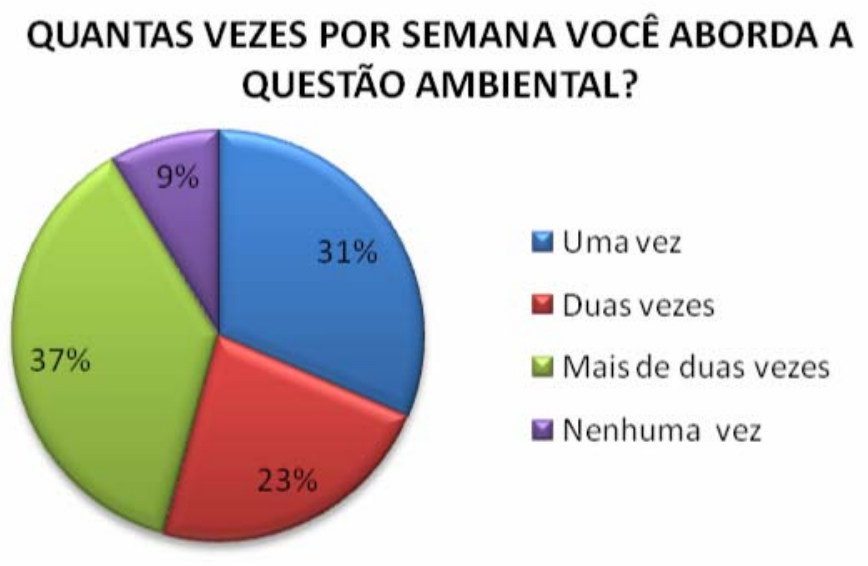

Figura 5 - Quantas vezes por semana você aborda a questão ambiental?

Na figura 5 observa-se que 37\% dos entrevistados abordam o tema mais de duas vezes por semana, porém as outras alternativas foram bastante escolhidas, mostrando que as escolas não oferecem aos professores um plano de ensino uniforme, com transparência da questão, e que deixe os docentes cientes da sua responsabilidade de tornar o meio ambiente saudável, e com garantias de boa qualidade para sobrevivência das gerações futuras. 


\section{SUA ESCOLA TEM EDUCAÇÃO AMBIENTAL?}

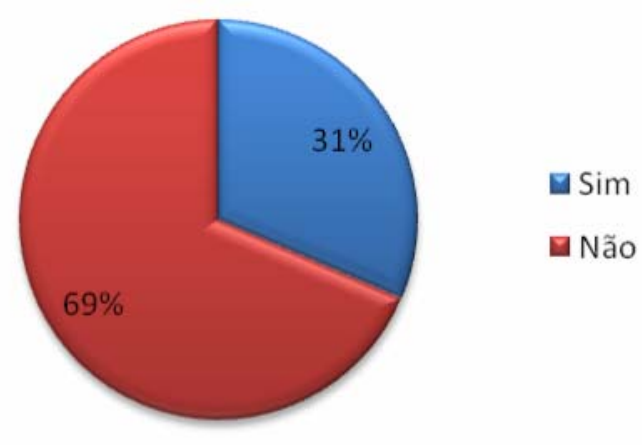

Figura 6 - Sua escola tem programa de Educação Ambiental?

A figura 6 mostra que, apesar de 31\% dos professores afirmarem que a escola tem programa de Educação Ambiental, mas a maioria (69\%) diz o contrário. Esses dados nos induzem a pensar que, a Secretaria de Educação do Município não está preocupada com a questão, e que no projeto político pedagógico (PPP) das escolas, sequer é vislumbrada essa questão.

\section{VOCÊ TEM CONHECIMENTO DE OUTROS COLEGAS QUE PRATICAM A EDUCAÇÃO AMBIENTAL?}

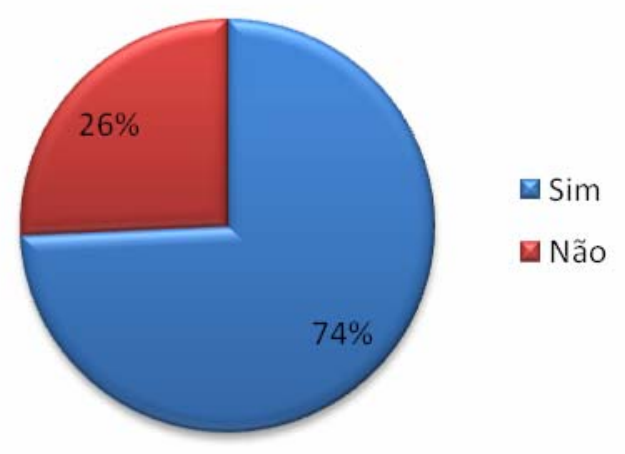

Figura 7 - Você tem conhecimento de outros colegas que praticam as questões ambientais?

A figura 7 mostra que, $74 \%$ dos professores conhecem colegas que de alguma forma pratica ações de preservação do meio ambiente e $26 \%$ não conhece, ou seja, a maioria dos educadores diz ter conhecimento de colegas que praticam as questões ambientais, porém essa prática acontece sem incentivo dos gestores, que não possuem uma interação entre os profissionais da área pedagógica, mostrando assim a fragilidade no projeto político pedagógico das escolas analisadas. 


\section{VOCÊ ACHA QUE NA SUA DISCIPLINAÉ FÁCIL APLICAR A QUESTÃO AMBIENTAL?}

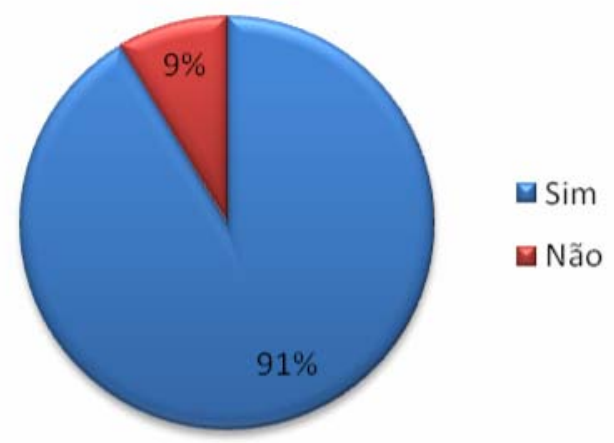

\section{Figura 8 - Você acha que na sua disciplina é fácil aplicar a questão ambiental?}

A figura 8 mostra que a maior parte os professores concordam que em sua disciplina é fácil trabalhar a questão ambiental, apenas 9\% dos professores das disciplinas História, Matemática e Física discordam da maioria, apontando que não é fácil trabalhar a temática em questão. Esses dados revelam que os professores têm noção da possibilidade de transmitir a EA através da sua disciplina, o que facilitaria a introdução do tema transversal na dinâmica escolar, falta apenas uma política no sentido de tornar efetiva a prática por todos da comunidade escolar.

\section{O QUE VOCÊ ACHA QUE FALTA PARA QUE ISSO ACONTEÇA?}

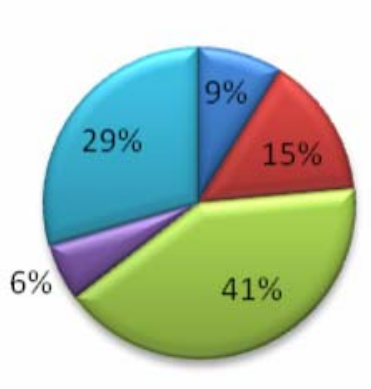

$\square$ Vontade política dos governantes e empenho dos professores

Vontade política dos governantes e participação da comunidade

๑ Participação de toda comunidade

Vontade politica dos governantes

घmpenho da direção da escola, dos professores, vontade política dos governantes e participação da comunidade

\section{Figura 9 - O que você acha que falta para que isto aconteça?}

A figura 9 mostra que é significativo a união dos governantes, o empenho dos diretores e professores, a participação de toda sociedade para fazer uma política geral de aplicabilidade, de forma mais ativa e, sobretudo, a implantação nos PPP de forma clara de atuação dos educadores, dos discentes e todo pessoal que faz a educação-cidadã, para que exista respeito com o meio ambiente. 


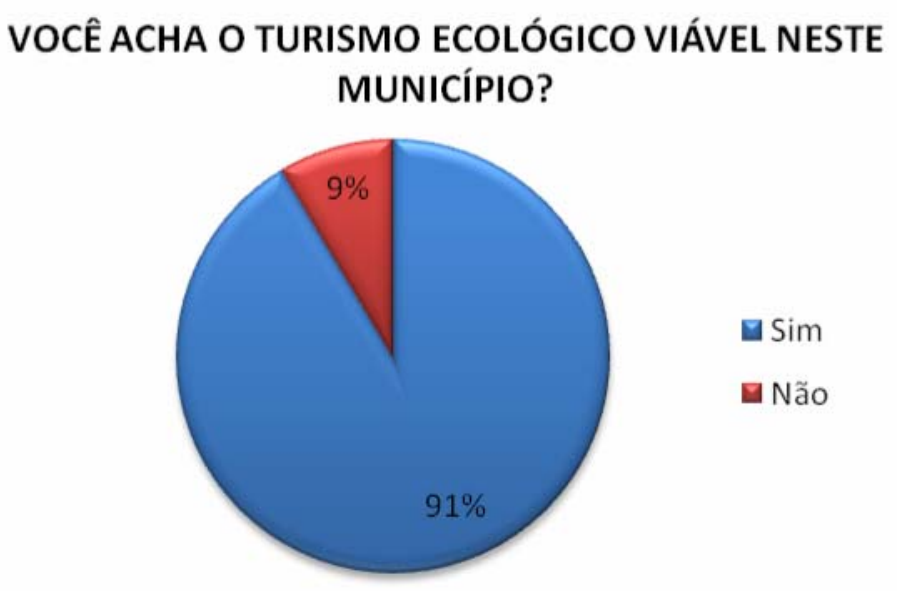

Figura 10 - Você acha o turismo ecológico viável neste município?

Na análise da figura 10 vê-se que 91\% dos professores acham que o turismo ecológico é viável neste município, e apenas $9 \%$ acha que não é importante; isto se deve ao fato de existir, na localidade, atrativos como a Serra do Torreão, que é uma reserva ecológica municipal descrita na lei orgânica de 03 de abril de 1990, cap.11, artigo 93, do município de João Câmara, possuindo 169m de altura acima do nível do mar. Porém, três professores das disciplinas Geografia, História e Português não acreditam que o turismo ecológico seja viável no município, mas não explicam as razões.

\title{
DE QUE MANEIRA OS ALUNOS DESTA ESCOLA PODERIAM CONTRIBUIR PARA O TURISMO ECOLÓGICO DA CIDADE?
}

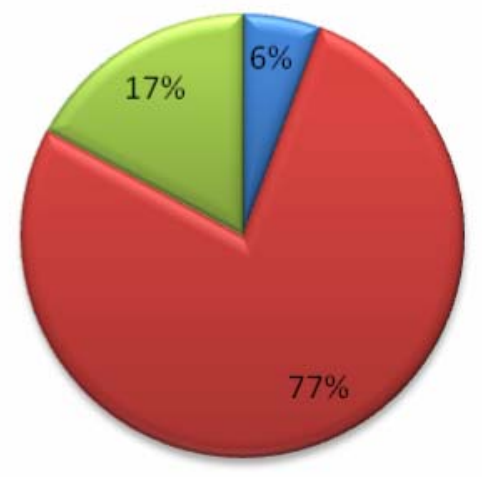

\author{
๑ Sendo guías turísticos \\ Atuando como vigilantes \\ permanentes do M. A. \\ $\square$ Sendo guías turísticose \\ atuando como vigilantes \\ permanentes do M. A.
}

Figura 11 - De que maneira os alunos desta escola poderiam contribuir para o turismo ecológico na sua cidade?

A figura 11 revela dados que mostram a percepção que os professores tiveram para com a realidade em que estão inseridos os seus alunos, com relação à contribuição do turismo ecológico na cidade de João Câmara - RN. A maioria (77\%) dos professores optou pela alternativa dos mesmos atuarem como vigilantes do meio ambiente, tendo em vista que essa escolha serviria não apenas para os visitantes ou turistas, e sim para o bem estar de toda a comunidade. Uma minoria (6\%) dos entrevistados acha que seus alunos têm potencial para serem guias turísticos, esse baixo índice talvez seja pela falta dessa atividade atualmente. 


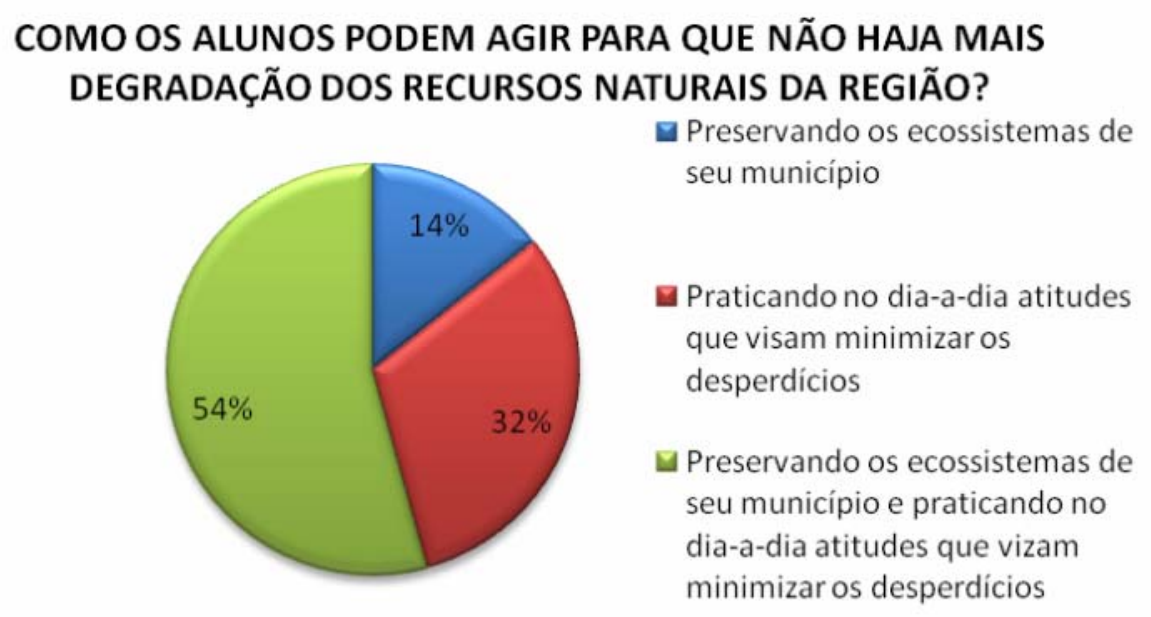

\section{Figura 12 - E para que não haja mais degradação dos recursos naturais de sua região?}

A figura 12 nos mostra que é possível verificar a preocupação de preservar os ecossistemas de seu município e praticar atitudes, no dia-a-dia, que visão minimizar os desperdícios; em sua maioria os professores foram coerentes ao ver a relação entre o meio ambiente e a sociedade por completo, ou seja, que uma ação está relacionada a outra.

Todos responderam positivamente com relação ao trabalho interdisciplinar como forma de tratar as questões ambientais, já que a EA pode ser praticada conjuntamente em todas as áreas do ensino, de forma a dinamizar a construção do saber, tornando a EA uma prática real.

\section{CONCLUSÃO}

A realização deste trabalho teve como objetivo de pesquisa estudar o desenvolvimento da prática pedagógica relacionada à Educação Ambiental nas escolas públicas do centro de João Câmara-RN, no nível médio de escolaridade. Diante do estudo realizado percebemos que o trabalho pedagógico sobre o meio ambiente no Colégio Cenecista João XXIII é abordado de forma interativa levando os alunos a conhecerem um pouco as práticas da Educação Ambiental através do grupo ecológico, que tem por objetivo promover a conservação dos ecossistemas do município e formar vigilantes permanentes do meio ambiente, engajados com projetos que visam proteger os animais silvestres da região. Já nas outras duas escolas, Escola Estadual Antônio Gomes e Escola Estadual Francisco de Assis Bittencourt, não se encontra nenhum programa nesse sentido.

Ficou claro com a nossa pesquisa que a maioria dos professores tem consciência de que não é difícil trabalhar a Educação Ambiental nas suas disciplinas, porém a falta de um projeto político pedagógico que contemple a temática é notória, nas três escolas pesquisadas.

\section{Fica, portanto, como sugestões:}

Que os professores se empenhem mais na aplicação da prática da Educação Ambiental para que esta deixe de ser um tema transversal só na teoria e passe a ser praticamente realmente; 
Aos professores de Língua Portuguesa, recomenda-se que tragam para a sala-de-aula textos relacionados ao meio ambiente; aos de História, que estimulem a leitura reflexiva dos acontecimentos ecológicos passados e presentes, comparando-os; aos de Matemática, que estimulem os alunos a pensar sobre quantidades, envolvendo temas ambientais, para que estes possam transformá-lo; em Biologia podem ser abordados os ciclos da água, nitrogênio, carbono e até mesmo as doenças decorrentes da falta de saneamento, disposição incorreta do lixo, entre outros problemas oriundos da falta de preservação do meio ambiente; na disciplina de Física, podem ser tratados os fenômenos que hoje vêm ocorrendo com muito mais intensidade na natureza, bem como abordar a questão das energias alternativas, etc; em Química pode ser analisada a questão do uso indiscriminado dos agrotóxicos; em Inglês, devem ser utilizados textos que tratem sobre inovações tecnológicas na área ambiental, catástrofes ambientais, turismo ecológico, etc;

À Secretaria Municipal de Educação da cidade de João Câmara deve orientar e exigir dos diretores das escolas que façam valer o que orienta os PCNs, e dê condições práticas, como treinamento de pessoal para a realização efetiva da multidisciplinaridade do tema, pois é necessário que todos professores estejam envolvidos, para que um maior número de aluno seja orientado a preservar o meio em que vivem, e assim tornarem-se multiplicadores em suas casas, juntos aos familiares, visinhos e outras pessoas mais próximas do seu convívio.

\section{REFERÊNCIAS BIBLIOGRÁFICAS}

BERNA, Vilmar. Como fazer educação ambiental. 2. ed. São Paulo: Paulus, 2004.

BRASIL, Câmara dos deputados. Constituição da república federativa do Brasil. Brasília: [s.n.], 1988.

CRESPO, Antônio Arnot. Estatística fácil. 18. ed. São Paulo: Saraiva, 2004.

FREIRE, Paulo. Pedagogia da autonomia. 31. ed. São Paulo: Paz e Terra, 2005.

MAIA, Lerson F. dos Santos. Trabalhos acadêmicos: princípios, normas e técnicas. Natal: CEFET - RN, 2005.

MORIN, Edgar. Os sete saberes necessários à educação do futuro. 11.ed. São Paulo: Cortez, 2005.

PEDRINI, Alexandre Gusmão (ORG). Educação ambiental - Reflexões e práticas contemporâneas. 5. ed. Petrópolis: Vozes, 2002.

\section{Sites visitados:}

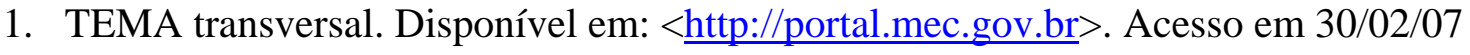

2. EDUCAÇÃO. Disponível em: <http://www.educacional.com.br/projetos $>$. Acesso em 30/02/07

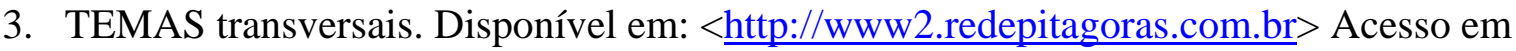
30/02/07

4. PCNs. Disponível em: http://www.udemo.org.br/jornalpp Acesso em 30/02/07 